\title{
Ormancılık Sektöründe İklim Değişikliğinin Etkilerini Stratejilerine İlişkin Görüşler
}

\author{
Mehmet KORKMAZ $^{1 *}$, Ozan Arif ADIGÜZEL ${ }^{2}$ \\ 1* Isparta Uygulamalı Bilimler Üniversitesi, Orman Fakültesi, Orman Mühendisliği Bölümü, 32260, Isparta \\ 2 Isparta Orman Bölge Müdürlüğü, Sütçüler Orman İşletme Müdürlüğü, 32950, Isparta
}

\section{Öz}

Ormanlar mevcut karbonu koruma, daha fazla karbon depolama ve karbon ikamesi ile iklim değişikliğinin etkilerinin azaltılmasında önemli role sahip ekosistemlerdir. Bu bağlamda orman kaynaklarının karbon yönetim stratejilerini belirlemek ve önceliklendirmek önem arz etmektedir. Bu çalışmanın amacı, ormancılık sektöründe iklim değişikliğinin etkilerini azaltma stratejilerine yönelik öncelikleri belirlemek ve bu öncelikleri değerlendirmektedir. Veriler, orman mühendislerinden anket yöntemiyle elde edilmiştir. Verilerin analizi için yüzde, frekans ve bazı özelliklere (yaş, eğitim, görev yılı vb.) göre farklılıkların belirlenmesinde ki-kare testi kullanılmıştır. Stratejilere yönelik öncelikler, Friedman ve Wilcoxon testi ile belirlenmiştir. Çalışma sonuçlarına göre rehabilitasyon, büyüme oranını artırma ve yaşlı ormanları koruma en önemli stratejilerdir. Tüm stratejiler arasında tek desteklenmeyen strateji, hasadı artırmadır. Bunun yanında hasadı azaltma ve idare sürelerini artırma stratejileri de düşük düzeyde desteklenmektedir. Bu belirlemelere göre orman mühendislerince desteklenen karbon temelli orman yönetim stratejilerinin daha çok koruma hedefiyle uyumlu olduğu görülmektedir. Buna karşın ikame ürün üretimi olarak ahşap kullanımının yaygınlaştırılması için hasat temelli stratejilere destek ise düşük düzeydedir.

Anahtar Kelimeler: Rehabilitasyon, biyoenerji, hasadı artırma, karbon azaltımı.

\section{Opinions about Climate Change Mitigation Strategies in Forestry Sector}

\begin{abstract}
Forests are ecosystems that have an important role in climate change mitigation by protecting existing carbon, more carbon storage and carbon substitution. In this context, it is important to determine and prioritize the carbon management strategies of forest resources. The aim of this study is to determine the priorities for the strategies to climate change mitigation in the forestry sector and to evaluate these priorities. Data were obtained from forest engineers by survey method. For the analysis of the data, the chi-square test was used to determine the differences according to the percentage, frequency and some characteristics (age, education, year of employment, etc.). Priorities for strategies were determined by the Friedman and Wilcoxon test. According to the results of the study; rehabilitation, increasing the growth rate and protecting old forests are the most important strategies. Of all the strategies, the only unsupported strategy is to increase the harvest. In addition, strategies to reduce harvest and increase rotation ages are also supported at a low level. According to these determinations, it is seen that carbonbased forest management strategies supported by forest engineers are more compatible with the protection target. On the other hand, the level of support for harvest-based strategies to expand the use of wood within the scope of substitute product production is low.
\end{abstract}

Keywords: Rehabilitation, bioenergy, increasing harvest, carbon mitigation. 


\section{Giriş}

Birleşmiş Milletler İklim Değişikliği Çerçeve Sözleşmesi’nde iklim değişikliği; "karşılaştırılabilir zaman dilimlerinde gözlenen doğal iklim değişikliklerine ek olarak, doğrudan veya dolaylı olarak küresel atmosferin bileşimini bozan insan faaliyetleri sonucunda iklimde oluşan değişiklik" şeklinde tanımlanmaktadır (URL-1, 2021). İnsan faaliyetleri, Dünya’nın yüzeyini ve atmosferik bileşimini geçmişten günümüze değiştirmeye devam etmektedir. Bu değişikliklerin bazıları (fosil yakıt kullanımı, sanayileşme, ormansızlaşma vb.), Dünya'nın enerji dengesi üzerinde doğrudan veya dolaylı bir etkiye sahip olup iklim değişikliğinin itici güçleridir (IPPC, 2013).

İklim değişikliğinin en önemli nedeni sera gazlarındaki artıştır. Karbondioksit $\left(\mathrm{CO}_{2}\right)$, metan $\left(\mathrm{CH}_{4}\right)$ ve nitroz oksit $\left(\mathrm{N}_{2} \mathrm{O}\right)^{\prime}$ in atmosferik konsantrasyonları, insan faaliyetleri nedeniyle 1750'den itibaren sürekli artmıştır. 2011 yılında bu gazların konsantrasyonları sanayi öncesi seviyelerine göre sırasıyla yaklaşı \%40, \%150 ve \%20 oranında artış göstermiştir (IPCC, 2013). Bu kapsamda iklim değişikliği ile mücadelede sera gazı emisyonunu azaltmak ve yeryüzündeki karbonu tutmak önemlidir. Orman kaynakları hem yeryüzündeki karbonunun hem de atmosferdeki sera gazlarının tutulması işlevleri ile iklim değişikliğiyle mücadele ve iklim değişikliğinin olumsuz etkilerinin azaltılması açısından önemlidir (Zeydanlı vd., 2010).

Orman kaynaklarının iklim değişikliği ile mücadelede oynadığı rol, ülkemizin ormancılık ile ilgili üst politika belgelerine de yansımıştır. On Birinci Kalkınma Planı'nda (SBB, 2019) “ahşap kullanımının yaygınlaştırılması ve odun hammaddesi talebinin karşılamasına yönelik endüstriyel plantasyonların kurulması” hedefi belirlenmiştir. Yine 2010-2023 yılları arasını kapsayan Türkiye İklim Değişikliği Stratejisi’nde (ÇŞB, 2010) iklim değişikliği ile mücadele ve uyum etkinliklerine yönelik orman kaynaklarında birtakım önlemlerin alınması gerekliliği belirtilmiş, “Türkiye Cumhuriyeti İklim Değişikliği Eylem Planı”nda (ÇŞB, 2012) bu önlemlere yer verilmiştir. Benzer şekilde “Çölleşme ile Mücadele Ulusal Stratejisi ve Eylem Planı”, "Ulusal Biyolojik Çeşitlilik Strateji ve Eylem Planı” ve “Ulusal Havza Yönetim Stratejisi”nde iklim değişikliği ile mücadele konusunda kararlar bulunmaktadır (ÇMUSEP, 2019; ÇOB, 2008; OSB, 2014).

İklim değişikliğinin yol açtığı afetler (kuraklık, seller, kasırgalar, aşırı hava olayları vb.) etkisini giderek artırdıkça toplumların iklim değişikliği ve küresel ısınma duyarlılıkları artmaktadır. Öyle ki bu konular hakkında toplumun bilgi, bilinç, alg1 ve tutum düzeylerinin belirlenmesine yönelik çalışmalar yapılmaktadır (Alkan ve Özçelik, 2019; Aladağ vd., 2018; Korkmaz, 2018; Steentjes vd., 2017; Withana, 2014; Lejano vd., 2013; Westerhoff ve Robinson, 2013: Randall, 2009; Semenza vd., 2008). Bu çalışmaların büyük bir bölümünde iklim değişikliğinin en önemli nedenlerinden birisi ormansızlaşma olarak gösterilerek ormanların iklim değişikliği ile mücadeledeki rolüne vurgu yapılmıştır. Ekosistemin en büyük bileşenlerinden birisi olan ormanlar ve ormanların yönetimi de iklim değişikliği açısından büyük önem arz etmektedir. Gelişmekte olan ülkelerdeki ormansızlaşmadan ve orman bozulmasından kaynaklanan salımların azaltılması; orman karbon stoklarının korunması, ormanların sürdürülebilir yönetimi ve orman karbon stoklarının artırılmasını kapsayan REDD+ ve arazi kullanım sınıfları (orman, tarım, çayır/mera, sulak alan, iskân ve diğer alan) arasında zaman içerisinde insan müdahalesiyle yapılan değişikliklerin, sera gazı emisyonları ve azaltımları üzerindeki etkisini belirlemeyi hedefleyen AKAKDO süreçleri bu önemin uluslararası düzeydeki göstergelerindendir (Serengil, 2018; Başsüllü vd., 2014).

İklim değişikliğinin etkilerini azaltmada ormancılık etkinlikleri açısından üç temel yaklaşım bulunmaktadır. Bu yaklaşımlar (Nunes vd., 2019; Canadell ve Rapuach, 2008'e atfen Zeydanlı vd., 2010; Brown vd., 1996);

- Mevcut karbonu koruma: Depolanan karbon miktarlarının yalnızca, esas olarak hammaddelerin endüstriyel kullanımıyla salınan karbonun yerini aldığı yaklaşım (Ormansızlaşmayla mücadele, mevcut orman alanlarını koruma vb.),

- Daha fazla karbon depolama: Depolanan karbon miktarının artmasını sağlamak için orman alanlarının ve verimliliğinin artmasını destekleyen yaklaşım (Ağaçlandırma ve rehabilitasyon çalışmaları, ormanların karbon bağlama kapasitesinin artırılması için gerekli önlemleri alma vb.) ve

- Karbon ikamesi: Fosil karbonun yenilenebilir karbon ile ikame edilmesine doğru ilerleyen ve böylece nötr bir akışın yaratılmasına katkıda bulunan yaklaşım (Orman ürünlerinin kullanım alanlarının artırılması ve teşvik edilmesi, bu sayede fosil tabanlı ürünlerin yerine ikamesinin sağlanması ve $\mathrm{CO}_{2}$ salımının önüne geçilmesi) şeklinde sıralanmaktadır.

İlk iki yaklaşım ağırlıklı olarak “düzenleyici” özellikte iken, üçüncü yaklaşım “engelleyici” rol üstlenmektedir (Gürlevik ve Karatepe, 2005). Yaklaşımların tümü orman kaynaklarının, sağladığı diğer faydaların yanında karbon amaçlı yönetiminin gerekliğini ortaya koymaktadır. Bu makalede, yukarıda belirtilen yaklaşımlar çerçevesinde ormancılık sektöründe iklim değişikliğinin etkilerini azaltma stratejilerine yönelik değerlendirmeler yapılmıştır. Belirlenen stratejilere ilişkin önem düzeyleri (öncelikleri) orman mühendislerinin görüşleri 
bağlamında belirlenmiş, orman mühendislerinin bazı özelliklerine (yaş, eğitim, görev yılı vb.) göre bu öncelikler arasındaki farklılıklar ortaya konulmuş ve orman yönetimi stratejilerinin belirlenmesinde etkili olan etmenler değerlendirilmiştir.

\section{Materyal ve Metot}

Çalışmada iklim değişikliğinin etkilerini azaltmada orman kaynaklarının yönetimi için sekiz farklı strateji belirlenmiştir. Bu stratejilerin belirlenmesinde Peterson St-Laurent vd. (2018)'den faydalanılmış olup stratejilere yönelik açıklamalara aşağıda yer verilmiştir;

1. Biyoenerji stratejisi: Endüstriyel odun hammaddesi üretiminde hasat sırasında toplanmayan ve ormanda çürümeye terk edilen hasat artıkları veya yakacak odunun doğrudan biyoenerji üretiminde kullanılması (Yararları: Üretimi ve kullanımı daha fazla net sera gazı emisyonu ve iklim değişikliği oluşturan fosil yakıtlar yerine biyoenerjinin kullanımı),

2. Hasat etkenliği stratejisi: Endüstriyel odun hammaddesi üretiminde hektar başına daha fazla odun elde etme ve hasat edilen ürünler için hasat etkenliğini artırma, böylelikle hasat edilen toplam alanı azaltma (toplam hacimde değişiklik olmadan) (Yararlarl: hasat edilen alanı azaltma ve bu sayede tutulan karbonun bir kısmının ormanda kalmasını sağlama),

3. Hasadı azaltma stratejisi: Odun hammaddesi üretim ormanlarını azaltma (Avantajı: Yönetilen ormanlarda bulunan mevcut karbonu koruma),

4. Hasadı artırma stratejisi: Odun hammaddesi üretim ormanlarını arttırma (Avantajı: Üretimi ve kullanımı daha fazla sera gazı emisyonu ve iklim değişikliği oluşturan diğer ürünlerin yerine kullanılabilecek daha fazla endüstriyel odun üretme),

5. Büyüme oranını artırma stratejisi: Çeşitli tekniklerle (örneğin, ıslah edilmiş tohumlar veya ağaç türlerinin kullanımı, gübreleme vb.) ağaçların büyüme oranını mevcut seviyelerin üzerine çıkarma (Yararları: Ăgaçların daha hızlı büyümesi ve bu sayede atmosferdeki karbonu daha hızlı tutması),

6. İdare sürelerini artırma stratejisi: İnşaat vb. sektörlerde kullanılmak üzere uzun idare süreli ürünler (tomruk vb.) üretme (Yararları: (1) Odun ürünlerinde karbonun depolandı̆̆ süreyi arttırmak ve (2) üretimi ve kullanımı daha fazla sera gazı emisyonu ve iklim değişikliği oluşturan diğer ürünler (çimento, demir vb.) yerine odun ürünleri kullanımını săglama),

7. Yaşlı ormanları koruma stratejisi: Yaşlı ormanlarda endüstriyel odun üretiminin yapılmaması (Yararı: Yaşlı ormanları yüksek miktarda karbonla korumak),

8. Rehabilitasyon stratejisi: Bozuk meşcerelerde ve orman içi boşluklarda rehabilitasyon çalışmaları yapmak (Yararl: Atmosferdeki karbonu daha hızlı ve fazla miktarda tutma).

Çalışmada veriler anket yoluyla toplanmıştır. Anket formları iki bölümden oluşmaktadır. İlk bölümde, anket çalışmalarına katılan orman mühendislerinin cinsiyet, yaş, görev yılı, eğitim düzeyi (lisans, yüksek lisans, doktora) ve görev yapılan sektöre ilişkin verilerin elde edilmesine yönelik sorular bulunmaktadır. İkinci bölümde ise iklim değişikliğinin etkilerini azaltma ile ilgili olarak orman kaynaklarının yönetim stratejilerinin değerlendirilmesine ve bu stratejilerin uygulamalarına yönelik ifadelere yer verilmiştir. Stratejilerin değerlendirilmesine ilişkin ifadelerin yanıtları için beşli Likert ölçeği $(-2=$ Kesinlikle karşıyım, $-1=$ Karşıyım, $0=\mathrm{Ne}$ karşıyım ne de destekliyorum, 1=Destekliyorum, 2=Kesinlikle destekliyorum) kullanılmıştır.

Son hali verilen anket formlarının uygulanması için Isparta Uygulamalı Bilimler Üniversitesi Bilimsel Araştırma ve Yayın Etiği Kurulunun 26.10.2020 tarih ve 33/01 nolu kararı gereğince etik kurul izni alınmıştır. Örnek büyüklüklerinin belirlenmesinde sınırlı toplumlarda kullanılan ve aşağıda açıklanan eşitlikten (1) faydalanılmıştır (Baş, 2010);

$n=\frac{N t^{2} p q}{d^{2}(N-1)+t^{2} p q}$

Burada;

n: Örnek büyüklüğünü,

t: Belirli bir anlamlılık düzeyinde t tablosuna göre bulunan teorik değer (\%95 güven düzeyi için 1,96),

$\mathrm{N}$ : Ana kütle büyüklüğünü,

p: Ölçmek istenilen büyüklüğün ana kütlede bulunma olasılığını $(0,5)$,

q: Ölçmek istenilen büyüklüğün ana kütlede bulunmama olasılı̆̆ını $(0,5)$,

$\mathrm{d}$ : Kabul edilen örnekleme hatasını (Bu çalışmada \%7 olarak alınmıştır) göstermektedir. 
Yukarıdaki formüle göre hesaplanan örnek büyüklüğü, asgari 194 kişi olarak belirlenmiş olup, 241 orman mühendisi anket çalışmalarına katılmıştır. Anket çalışmalarına katılan orman mühendislerine ilişkin bazı bilgiler (cinsiyet, yaş, görev yılı, eğitim düzeyi ve görev yapılan sektör) Tablo 1'de gösterilmiştir.

Tablo 1. Anket çalışmalarına katılan orman mühendislerine ilişkin bazı bilgiler.

\begin{tabular}{cll}
\hline Cinsiyet & Sayı & \% \\
\hline Kadın & 50 & 20,7 \\
Erkek & 191 & 79,3 \\
\hline Yaş Grupları & Sayı & \% \\
\hline$\leq 25$ & 17 & 7,1 \\
$26-45$ & 149 & 61,8 \\
$46-65$ & 75 & 31,1 \\
\hline Görev yılı & Sayı & \% \\
\hline $1-5$ yıl & 75 & 31,1 \\
$6-10$ yıl & 30 & 12,5 \\
$11-15$ yıl & 26 & 10,8 \\
$16-20$ yıl & 27 & 11,2 \\
$>20$ yıl & 83 & 34,4 \\
\hline Ĕ̆itim düzeyi & Sayı & $\mathbf{\%}$ \\
\hline Lisans & 141 & 58,5 \\
Yüksek lisans & 52 & 21,6 \\
Doktora & 48 & 19,9 \\
\hline Görev yapılan sektör & Sayı & $\mathbf{\%}$ \\
\hline Ormancılık ile ilgili kamu sektörü & 128 & 53,1 \\
Üniversite & 62 & 25,7 \\
Ormancılık ile ilgili özel sektör & 26 & 10,8 \\
Diğer (özel sektör) & 16 & 6,7 \\
Diğer (kamu) & 9 & 3,7 \\
\hline
\end{tabular}

Veri analizinde öncelikle frekanslar ve yüzde dağılımlar hesaplanarak çapraz tablolar oluşturulmuştur. Ardından Shapiro-Wilk testi sonuçlarına göre verilerin \%95 $(\mathrm{p}<0,05)$ güven düzeyinde normal dağılım göstermediği yani parametrik veri olmadığı belirlendiği için ki-kare testi ile orman mühendislerinin verdikleri yanıtların, cinsiyet, yaş, görev yılı, eğitim düzeyi ve görev yapılan sektöre göre farklı olup olmadığı araştırılmıştır. Ardından stratejiler için beşli Likert ölçeğine göre verilen yanıtların aritmetik ortalamaları alınarak önem düzeyleri (öncelikleri) ortaya konulmuştur. Ortalamalar arasında istatistiksel olarak anlamlı farklılıkların olup olmadığı Friedman testi, bu testin sonucunda hangi stratejiler arasında farklılıkların olduğu Wilcoxon testi ile belirlenmiştir. Friedman testinin hipotezleri:

$\mathrm{H}_{0}$ : Orman mühendislerinin stratejileri destekleme düzeylerinde fark yoktur.

$\mathrm{H}_{1}$ : Orman mühendislerinin en az bir stratejiyi diğerlerine göre daha fazla desteklemektedir, şeklindedir.

\section{Bulgular}

\subsection{Stratejiler için destek düzeyi}

Belirlenen sekiz stratejiye yönelik değerlendirmeler sonucunda orman mühendislerinin bu stratejilere destek düzeylerinin dağılımı Tablo 2'de gösterilmiştir. Buna göre tüm stratejiler arasında "kesinlikle karşıyım” seçeneği seçme oranı; hasadı artırma $(\% 8,7)$ ve biyoenerji $(\% 8,3)$ stratejilerinde göreli olarak daha yüksektir. Hasadı arttırma stratejisi diğer tüm stratejilere göre en yüksek düzeyde karşı çıkılan $(\% 45,6)$ strateji olarak dikkati çekmektedir. 
Tablo 2. Stratejilere yönelik destek düzeylerinin dağılımı.

\begin{tabular}{|c|c|c|c|c|c|c|c|c|c|c|}
\hline \multirow[t]{2}{*}{ STRATEJILER } & \multicolumn{2}{|c|}{$\begin{array}{l}\text { Kesinlikle } \\
\text { karşıyım }\end{array}$} & \multicolumn{2}{|c|}{ Karşıyım } & \multicolumn{2}{|c|}{$\begin{array}{l}\text { Ne karşıyım ne de } \\
\text { destekliyorum }\end{array}$} & \multicolumn{2}{|c|}{ Destekliyorum } & \multicolumn{2}{|c|}{$\begin{array}{l}\text { Kesinlikle } \\
\text { destekliyorum }\end{array}$} \\
\hline & Sayı & $\%$ & Sayı & $\%$ & Sayı & $\%$ & Sayı & $\%$ & Sayı & $\%$ \\
\hline Biyoenerji & 20 & 8,3 & 30 & 12,5 & 50 & 20,7 & 78 & 32,4 & 63 & 26,1 \\
\hline Hasat etkenliği & 11 & 4,6 & 29 & 12,0 & 48 & 19,9 & 115 & 47,7 & 38 & 15,8 \\
\hline Hasadı azaltma & 8 & 3,3 & 38 & 15,8 & 58 & 24,1 & 96 & 39,8 & 41 & 17,0 \\
\hline Hasadı artırma & 21 & 8,7 & 89 & 36,9 & 50 & 20,8 & 61 & 25,3 & 20 & 8,3 \\
\hline Büyüme oranını artırma & 4 & 1,7 & 28 & 11,6 & 47 & 19,5 & 116 & 48,1 & 46 & 19,1 \\
\hline İdare sürelerini artırma & 8 & 3,3 & 33 & 13,7 & 76 & 31,5 & 107 & 44,4 & 17 & 7,1 \\
\hline Yaşlı ormanları koruma & 6 & 2,5 & 44 & 18,3 & 41 & 17,0 & 93 & 38,6 & 57 & 23,6 \\
\hline Rehabilitasyon & 9 & 3,7 & 16 & 6,7 & 15 & 6,2 & 115 & 47,7 & 86 & 35,7 \\
\hline
\end{tabular}

Bunun yanında stratejilere yönelik değerlendirmelerde yansız olma (ne karşııım ne de destekliyorum) oranı idare sürelerinin artırılması stratejisinde en yüksek $(\% 31,5)$ düzeydedir. Bunu hasadı azaltma ve hasadı artırma stratejileri izlemektedir. Stratejileri destekleme oranları incelendiğinde en yüksek destek \%83,4 ile rehabilitasyon stratejisine aittir. Bunu büyüme oranını artırma $(\% 67,2)$ ve hasat etkenliği $(\% 63,5)$ stratejileri takip etmektedir.

Stratejilere karşı çıkma veya destekleme düzeylerinin dağılımı farklılıklar göstermektedir. Bu bağlamda anket çalışmalarına katılan orman mühendislerinin cinsiyet, yaş, görev yılı, eğitim düzeyi ve görev yapılan sektöre göre stratejilere yönelik değerlendirmeleri arasında farklılık olup olmadığına ilişkin değerlendirmeler aşağıda sunulmuştur.

Yaş gruplarına göre ki-kare testi sonuçları Tablo 3’te verilmiş olup farklılık arz eden stratejilere yönelik değerlendirmeler aşağıda gösterilmiştir;

- Biyoenerji stratejisinin değerlendirilmesinde yaş grupları arasındaki farklılığın nedeni; 46-65 yaş grubunun bu stratejiye karşı çıkma oranının göreli olarak daha yüksek olmasıdır ( $\leq 25$ : \%11,76; 26-45: 15,43; 4665: \%33,34).

- Hasat etkenliği stratejisini en yüksek düzeyde destekleyenler 46-65 yaş grubudur (\%73,34). Ayrıca 26 yaşından küçük bireyler arasında bu strateji konusunda yansız olanlar (ne karşıyım ne de destekliyorum) daha yüksek düzeydedir $(\% 35,29)$.

- Hasat edilen miktarı azaltma stratejisini en yüksek düzeyde destekleyenler 26 yaşın altındaki orman mühendisleridir $(\% 70,58)$.

- Büyüme oranını artırma stratejisi konusunda en yüksek düzeyde yansızlık oranı (ne destekliyorum ne de karşıyım) 26 yaş altı mühendislerdedir $(\% 47,06)$. Bu aynı zamanda destekleme oranını da azaltmış durumdadir.

- Rehabilitasyon stratejisine verilen yanıtların yaş grupları arasındaki farklılığın nedeni ise 46-65 yaş grubu mühendisler arasında bu stratejiye karşı çıkanların $(\% 14,67)$ göreli olarak diğer yaş gruplarına göre $(\leq$ 25:5,88; 26-45: 8,72) daha yüksek olması ile açıklanabilir.

Tablo 3. Yaş gruplarına göre ki-kare testi sonuçları.

\begin{tabular}{|c|c|c|c|}
\hline Stratejiler & $\chi^{2}$ & sd* & $\bar{p}$ \\
\hline Biyoenerji & 18,964 & \multirow{8}{*}{8} & $0,015^{* *}$ \\
\hline Hasat etkenliği & 20,738 & & $0,008 * *$ \\
\hline Hasadı azaltma & 16,994 & & $0,030 * *$ \\
\hline Hasadı arttırma & 11,137 & & 0,194 \\
\hline Büyüme oranını artırma & 21,813 & & $0,005 * *$ \\
\hline İdare sürelerini artırma & 12,470 & & 0,131 \\
\hline Yaşlı ormanları koruma & 14,505 & & 0,070 \\
\hline Rehabilitasyon & 18,112 & & $0,020 * *$ \\
\hline
\end{tabular}

*sd: serbestlik derecesi, ${ }^{* *} p<0,05$

Cinsiyete göre stratejileri destekleme veya karşı çıkma oranları incelendiğinde sadece yaşlı ormanları koruma stratejisi istatistiksel olarak farklılık arz etmektedir (Tablo 4). Bu farklılığın nedeni, erkeklerin yaşlı ormanları 
koruma stratejisi konusundaki yansızlık oranının $(\% 18,85)$ daha yüksek olması ve kadınların ise bu stratejiyi daha yüksek düzeyde desteklemesinden (\%66) kaynaklanmaktadır.

Tablo 4. Cinsiyete göre ki-kare testi sonuçları.

\begin{tabular}{|c|c|c|c|}
\hline Stratejiler & $\chi^{2}$ & sd* & $\mathbf{p}$ \\
\hline Biyoenerji & 8,863 & \multirow{8}{*}{4} & 0,065 \\
\hline Hasat etkenliği & 5,934 & & 0,204 \\
\hline Hasadı azaltma & 4,483 & & 0,345 \\
\hline Hasadı arttırma & 4,834 & & 0,305 \\
\hline Büyüme oranını artırma & 2,796 & & 0,593 \\
\hline İdare sürelerini artırma & 7,156 & & 0,128 \\
\hline Yaşlı ormanları koruma & 15,063 & & $0,005 * *$ \\
\hline Rehabilitasyon & 3,144 & & 0,534 \\
\hline
\end{tabular}

*sd: serbestlik derecesi, ${ }^{* *} p<0,05$

Eğitim düzeyi (lisans, yüksek lisans ve doktora) itibariyle sadece hasat etkinliği stratejisi istatistiksel olarak farklılaşmaktadır (Tablo 5). Bunun nedeni, doktora eğitimini tamamlayan mühendislerin bu stratejiyi destekleme oranının (\%54,17), diğer gruplara göre (lisans: 65,96; yüksek lisans: 65,38) daha düşük düzeyde olmasıdır.

Tablo 5. Eğitim durumuna göre ki-kare testi sonuçları.

\begin{tabular}{|c|c|c|c|}
\hline Stratejiler & $\chi^{2}$ & sd* & $\mathbf{p}$ \\
\hline Biyoenerji & 7,083 & \multirow{8}{*}{8} & 0,528 \\
\hline Hasat etkenliği & 17,037 & & $0,030 * *$ \\
\hline Hasadı azaltma & 7,500 & & 0,484 \\
\hline Hasadı arttırma & 8,125 & & 0,421 \\
\hline Büyüme oranını artırma & 12,501 & & 0,130 \\
\hline İdare sürelerini artırma & 5,381 & & 0,716 \\
\hline Yaşlı ormanları koruma & 14,494 & & 0,070 \\
\hline Rehabilitasyon & 6,258 & & 0,618 \\
\hline
\end{tabular}

*sd: serbestlik derecesi, $* * p<0,05$

Görev yapılan alana göre büyüme oranını artırma stratejisinin değerlendirilmesi sonucunda ormancılığın özel sektöründe görev yapan mühendislerin bu stratejiye karşı çıkma oranı $(\% 7,69)$, diğer görev alanlardaki mühendislere göre daha düşüktür (Tablo 6). Ayrıca ormancılık dışı kamu $(\% 77,78)$ veya özel sektörlerde $(\% 75)$ görev yapan mühendisler bu stratejiyi göreli olarak daha yüksek düzeyde desteklemektedir. Tersine idare sürelerini artırma stratejisini destekleme oranı bakımından en düşük destekleme oranları ormancılık dışı kamu $(\% 44,44)$ ve özel sektörlerde $(\% 37,50)$ görev yapan mühendislere aittir. Yaşlı ormanları koruma stratejisine en yüksek düzeyde destek verenler, üniversite $(\% 75,81)$ ve ormancılık dışı kamu kurumlarında görev yapan mühendislerdir $(\% 77,78)$. Bunun yanında bu stratejiye en düşük düzeyde destek verenler, ormancılığın kamu alanında görev yapan mühendislerdir $(\% 54,69)$.

Tablo 6. Görev yapılan alana (sektör) göre ki-kare testi sonuçları.

\begin{tabular}{|c|c|c|c|}
\hline Stratejiler & $\chi^{2}$ & sd* & $\overline{\mathbf{p}}$ \\
\hline Biyoenerji & 9,738 & \multirow{8}{*}{16} & 0,880 \\
\hline Hasat etkenliği & 17,339 & & 0,364 \\
\hline Hasadı azaltma & 25,755 & & 0,058 \\
\hline Hasadı arttırma & 22,161 & & 0,138 \\
\hline Büyüme oranını artırma & 37,275 & & $0,002 * *$ \\
\hline İdare sürelerini artırma & 65,430 & & $0,000 * *$ \\
\hline Yaşlı ormanları koruma & 29,539 & & $0,021 * *$ \\
\hline Rehabilitasyon & 15,181 & & 0,511 \\
\hline
\end{tabular}

* sd: serbestlik derecesi, ${ }^{* *} p<0,05$ 
Biyoenerji stratejisini destekleme oranı görev yapılan yıl arttıkça düşmektedir (Tablo 7). Görev yılı 6-10 yıl arasında olan mühendislerde bu oran \%73,33 iken görev yılı 16-20 yıl olanlarda \%48,15'e, yirmi yıldan daha fazla görev yılına sahip mühendislerde ise \%50'ye gerilemektedir. Bu farklılık yaş grupları ile ilgili yapılan açıklamalarla benzerlik göstermektedir. Hasat etkenliğini en yüksek düzeyde destekleyenler, yirmi yıl üzerinde görev yapan mühendislerdir $(\% 77,11)$. Bu oran 6-10 yıl arasında görev yapan mühendislerde \%43,33'e kadar düşmektedir. Hasat edilen miktarı azaltma stratejisine karşı çıkma oranları, görev yılı arttıkça yükselmektedir. Yani görev yılı 1-5 yıl olan mühendislerde bu oran \%8 iken 6-10 yıl süre ile görev yapanlarda \%16,67, 11-15 yıl süre ile görev yapanlarda \%23,08, 16-20 yıl süre ile görev yapanlarda \%25,93 ve yirmi yıldan daha fazla süre ile görev yapanlarda \%26,51'dir. Büyüme oranını artırma stratejisi konusunda en yüksek düzeyde yansızlık oranı (ne destekliyorum ne de karşıyım) 1-5 yıl arasında görev yapan mühendislerdedir (\%30,67). Ayrıca 16-20 yıl arasında görev yapan mühendisler bu stratejiyi en yüksek düzeyde desteklemektedir $(\% 85,19)$. Yaşlı ormanları koruma stratejisini en yüksek düzeyde destekleyen 11-15 y1l süre ile görev yapan mühendisler $(\% 80,77)$ diğer gruplardan (Ort. \%59,84) ayrılmaktadır.

Tablo 7. Görev yapılan yıla göre ki-kare testi sonuçları.

\begin{tabular}{|c|c|c|c|}
\hline Stratejiler & $\chi^{2}$ & sd* & $\mathbf{p}$ \\
\hline Biyoenerji & 34,389 & \multirow{8}{*}{16} & $0,005^{* *}$ \\
\hline Hasat etkenliği & 31,200 & & $0,013 * *$ \\
\hline Hasadı azaltma & 38,735 & & $0,001 * *$ \\
\hline Hasadı arttırma & 24,544 & & 0,078 \\
\hline Büyüme oranını artırma & 32,310 & & $0,009 * *$ \\
\hline İdare sürelerini artırma & 24,006 & & 0,089 \\
\hline Yaşlı ormanları koruma & 27,856 & & $0,033 * *$ \\
\hline Rehabilitasyon & 25,398 & & 0,063 \\
\hline
\end{tabular}

*sd: serbestlik derecesi, **p<0,05

\subsection{Stratejilerin önem düzeyi ve stratejilerin belirlenmesinde etkili olan etmenler}

Friedman testinin sonuçlarına göre $\left(\operatorname{Ki}-\operatorname{kare}\left(\chi^{2}\right)=188,378\right.$, sd= 7, p=0,000), orman mühendislerinin stratejileri destekleme veya karşı çıkma düzeyleri farklı olup bu farklılık istatistiksel olarak anlamlıdır. Yani en az iki stratejinin önem düzeyi birbirinden farklıdır. Bu farklılığın kaynağını tespit etmek amacıyla yapılan Wilcoxon testi sonuçları Tablo 8'de verilmiştir. Stratejilerin ikili değerlendirilmesi sonucunda, rehabilitasyon ve hasadı artırma stratejileri diğer stratejilerden ayrılmaktadır $(\mathrm{p}<0,05)$. Bunun yanında diğer stratejiler arasında da farklılıklar bulunmakta olup bu farklılıklar Tablo 8'de görülmektedir.

Tablo 8. Wilcoxon testi sonuçları.

\begin{tabular}{|c|c|c|c|c|c|c|c|c|}
\hline Stratejiler & Biyoenerji & $\begin{array}{l}\text { Hasat } \\
\text { etkenliği }\end{array}$ & $\begin{array}{l}\text { Hasadı } \\
\text { azaltma }\end{array}$ & $\begin{array}{l}\text { Hasadı } \\
\text { artırma }\end{array}$ & $\begin{array}{l}\text { Büyüme } \\
\text { oranını } \\
\text { artırma } \\
\end{array}$ & $\begin{array}{l}\text { İdare } \\
\text { sürelerini } \\
\text { artırma } \\
\end{array}$ & $\begin{array}{l}\text { Yaşlı } \\
\text { ormanları } \\
\text { koruma } \\
\end{array}$ & Rehabilitasyon \\
\hline Biyoenerji & - & - & - & - & - & - & - & - \\
\hline Hasat etkenliği & $\begin{array}{l}Z=-0,526 \\
p=0,599\end{array}$ & - & - & - & - & - & - & - \\
\hline Hasadı azaltma & $\begin{array}{l}Z=-0,499 \\
p=0,618\end{array}$ & $\begin{array}{l}Z=-0,876 \\
p=0,381\end{array}$ & - & - & - & - & - & - \\
\hline Hasadı artırma & $\begin{array}{l}Z=--5,827 \\
p=0,000\end{array}$ & $\begin{array}{l}Z=-7,683 \\
p=0,000\end{array}$ & $\begin{array}{l}Z=-5,321 \\
p=0,000\end{array}$ & - & - & - & - & - \\
\hline $\begin{array}{l}\text { Büyüme } \\
\text { oranını artırma }\end{array}$ & $\begin{array}{l}Z=--1,838 \\
p=0,066\end{array}$ & $\begin{array}{l}Z=-1,587 \\
p=0,113\end{array}$ & $\begin{array}{l}Z=-2,289 \\
p=0,022\end{array}$ & $\begin{array}{l}Z=-8,660 \\
p=0,000\end{array}$ & - & - & - & - \\
\hline $\begin{array}{l}\text { İdare sürelerini } \\
\text { artırma }\end{array}$ & $\begin{array}{l}Z=-1,881 \\
p=0,060\end{array}$ & $\begin{array}{l}Z=-2,777 \\
p=0,005\end{array}$ & $\begin{array}{l}Z=-1,354 \\
p=0,176\end{array}$ & $\begin{array}{l}Z=-5,575 \\
p=0,000\end{array}$ & $\begin{array}{l}Z=-4,216 \\
p=0,000\end{array}$ & - & - & - \\
\hline $\begin{array}{l}\text { Yaşlı ormanları } \\
\text { koruma }\end{array}$ & $\begin{array}{l}Z=-0,429 \\
p=0,668\end{array}$ & $\begin{array}{l}Z=-0,182 \\
p=0,856\end{array}$ & $\begin{array}{l}Z=-1,225 \\
p=0,221\end{array}$ & $\begin{array}{l}Z=-6,522 \\
p=0,000\end{array}$ & $\begin{array}{l}Z=-1,165 \\
p=0,244\end{array}$ & $\begin{array}{l}Z=-2,303 \\
p=0,021\end{array}$ & - & - \\
\hline Rehabilitasyon & $\begin{array}{l}Z=-4,962 \\
p=0,000\end{array}$ & $\begin{array}{l}Z=-5,205 \\
p=0,000\end{array}$ & $\begin{array}{l}Z=-5,258 \\
p=0,000\end{array}$ & $\begin{array}{l}Z=-9,555 \\
p=0,000\end{array}$ & $\begin{array}{l}Z=-4,391 \\
p=0,000\end{array}$ & $\begin{array}{l}Z=-6,954 \\
p=0,000\end{array}$ & $\begin{array}{l}Z=-4,492 \\
p=0,000\end{array}$ & - \\
\hline
\end{tabular}

Tüm stratejiler arasında ortalama puanlara göre en yüksek destek düzeyi rehabilitasyon stratejisine ait iken bu stratejiyi, büyüme oranının artırılması ve yaşıı ormanların korunması stratejileri izlemektedir (Şekil 1). Hasadı artırma stratejisi ise karşı çıkılan tek stratejidir. Bunun yanında destek düzeyi çok düşük olan stratejiler, idare sürelerini artırma ve hasadı azaltmadır. Peterson St- Laurent vd. (2018) tarafindan Britanya Kolumbiyası 
ormancılık sektörü için yapılan çalışma ile bu çalışmanın bulgulara karşılaştırıldığında benzer sonuçlara ulaşılmakla birlikte hasadı arttırma stratejisine yönelik ortalama puanlar bu çalışmada negatif çıkmıştır $(-0,12)$. Yani bu strateji diğer yedi stratejiden farklı olarak desteklenmemektedir. Bunun yanında en yüksek desteğe sahip üç strateji her iki çalışmada da benzerdir. Britanya Kolumbiyası'nda yapılan bir diğer çalışmaya göre ise en yüksek azaltma potansiyeli hasat etkenliği, uzun dönemli ahşap ürünlerin kullanımının teşviki ve hasat artıklarının biyoenerji için kullanılması olarak belirlenmiştir (Xu vd., 2018).

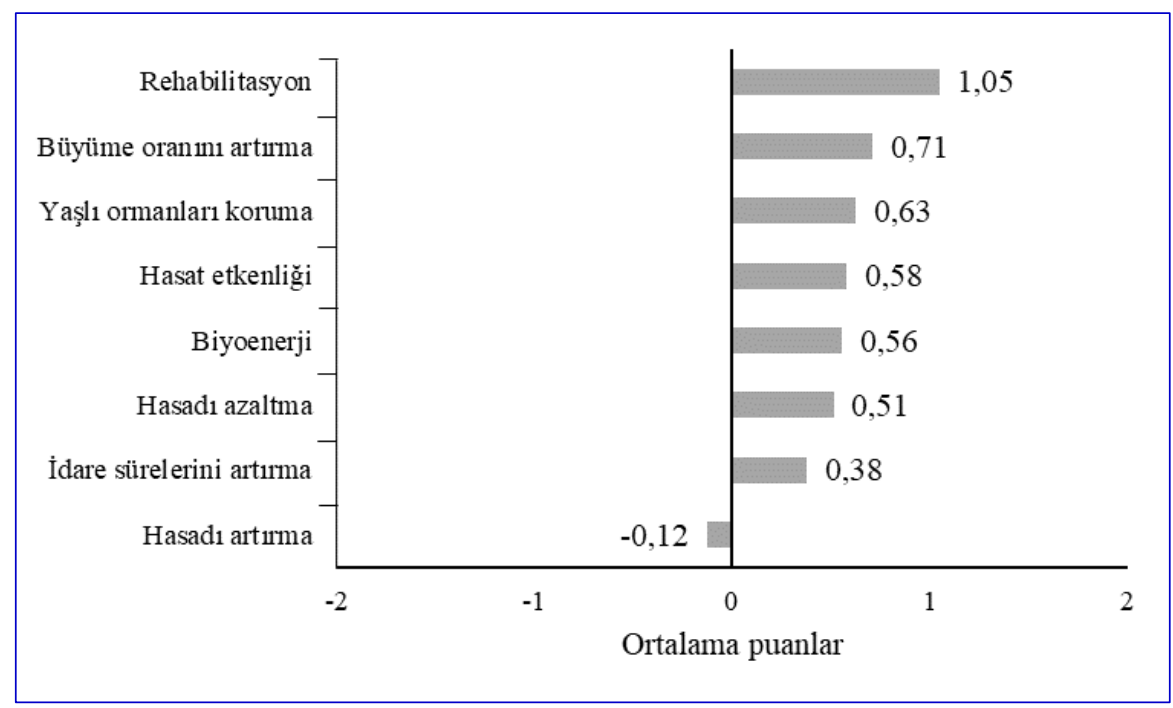

Şekil 1. Stratejilere destek veya karşı çıkma derecesini temsil eden ortalama puanlar $(-2=$ Kesinlikle karşıyım, $2=$ Kesinlikle destekliyorum).

Çalışmaya katılan orman mühendislerinin büyük bir bölümü, ormancılık sektöründe iklim değişikliğinin etkilerini azaltma stratejilerinin belirlenmesinde göz önünde bulunması gereken en önemli etmenin doğal tahribatları azaltmadaki etkileri olduğunu belirtmiştir. Bunu, iklim değişikliğini hafifletme ve biyolojik çeşitlilik üzerindeki etkiler izlemektedir. İklim değişikliği stratejilerinin maliyetleri ve yerel topluluklar üzerindeki ekonomik etkileri daha düşük düzeyde önemsenen etmenlerdir. Yani ekolojik etkiler, ekonomik etkilere göre daha önemli olarak görülmektedir. Peterson St-Laurent vd. (2018) tarafından yapılan çalışmada da benzer sonuçlara ulaşılmıştır.

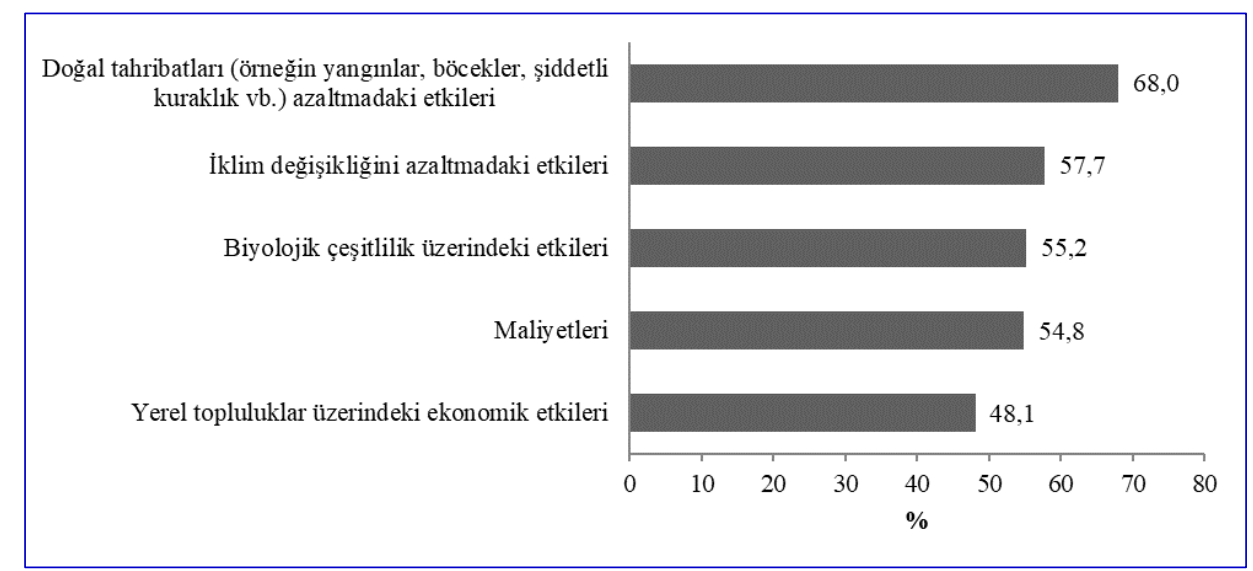

Şekil 2. Orman yönetimi stratejilerini belirlerken etkili olan/olabilecek etmenler (Birden fazla seçenek işaretlenmiştir).

\section{Tartışma ve Sonuç}

Bu çalışmada ormancılık sektörünün iklim değişikliğinin etkilerini azaltma stratejilerine yönelik değerlendirmeler yapılmıştır. Genel olarak görüşlerine başvurulan orman mühendislerinin orman kaynaklarında karbon birikimini sağlayan stratejilere daha yüksek düzeyde destek verdikleri görülmüştür. Belirlenen sekiz stratejinin sadece biri 
hariç tüm stratejiler değişen oranlarda desteklenmiştir. Karşı çıkılan hasadı artırma stratejisi olmuştur. En yüksek düzeyde desteklenen yani stratejiler arasında göreli olarak en önemli görülen strateji, rehabilitasyondur. Bunu büyüme oranının artırılması ve yaşlı ormanların koruması stratejileri izlemektedir. Ülkemiz ormanlarının yaklaşık \%42'si boşluklu kapalı koru veya baltalık orman niteliğindedir (OGM, 2021). Bu alanların bir bölümü ekolojik koşulları itibariyle bu özelliklere sahipken bazı alanlar ise başta yanlış arazi kullanımı gibi antropojen etkilerle bu hale gelmiştir. Bu alanlarda biyolojik çeşitliliğin korunması ve genetik kirlenmeye yol açmama konusunda özen gösterilerek rehabilitasyon çalışmaları yapılarak normal orman (verimli orman) yapısına dönüştürülmesi çalışmaları geçmişten günümüze devam etmekte olup OGM Stratejik Planı'nda da önümüzdeki yıllara yönelik hedefler konulmuş durumdadır (OGM, 2018). Bu durum halen rehabilitasyona ihtiyaç bulunan önemli miktarda alanın olduğunu göstermektedir (Çalışkan ve Boydak, 2017). Duyar (2018)'a göre, ülkemiz koşullarında meşe türleri ile kızılçam ve karaçam rehabilitasyon çalışmaları, karbon birikimine en fazla katkıyı yapabilecek durumdadır. Rehabilitasyon çalışmaları ile bozuk nitelikli orman alanlarının karbon depolama kapasitesinin arttırılması ve karbon yönetiminin ormancılık sektöründe yerini alması önem arz etmektedir (Tolunay, 2011).

Doğal yaşlı ve kalın çaplı ormanların korunması da karbon depolaması için önemli bir stratejidir. Yapılan bazı çalışmalarda da mevcut kalın çaplı ağaçlar ile yakın gelecekte büyük çaplara ulaşabilecek olan ağaçlardan oluşan meşcerelerin korunması gerekliliği vurgulanmıştır (Moomaw vd., 2019; Lutz vd., 2018). Oregon ve Washington'da yer alan Cascade dağlarında yaşlı ve kalın çaplı ağaçların yerüstü karbon depolamasına yaptığı katkı ve yoğun hasattan kaynaklanan karbon stoklarındaki azalmanın analiz edildiği bir çalışmada $53 \mathrm{~cm}$ 'den kalın çaplı ağaçların ormanın \%3'ünü oluşturmasına rağmen toplam yer üstü karbonun \%42'sini depoladığı ve bu bağlamda karbon stoklarına çok yüksek düzeyde katkı yaptıkları belirlenmiştir (Mildrexler vd., 2020).

Bir diğer önemli strateji, biyoenerji üretimi için hasat artıklarının kullanımıdır. Alkan vd. (2014)’e göre ülkemizde üniversite akademik personeli ve araştırma enstitüleri çalışanları ile uygulamacıların hasat artıklarından biyokütle üretiminin yaygınlaştırılmasına yönelik görüşleri olumlu yöndedir. Hasat artıklarının rasyonel olarak toplanıp biyokütle hammaddesi olarak enerji üretiminde kullanılması özellikle gelişmekte olan ülkeler için ekonomik, sosyal ve çevresel faydalar sunabilmektedir (Eker vd., 2017). Buna karşın ülkemizde odunsu biyokütleye dayalı biyoenerji üretimi henüz yeterli düzeyde geliştirilememiştir. Gelişmenin önündeki en önemli engel, yonga levha endüstrisinin artan talebidir (Eker, 2014). Ayrıca hammadde temininin sürekliliği konusundaki belirsizlik de önem arz etmektedir. Hammadde sıkıntısı sadece gelişmekte olan ülkeler için bir sınırlayıcı değildir. Almanya ve Birleşik krallık gibi bazı Avrupa ülkelerinde de biyoenerjiyi geliştirme hedefleriyle ilgili olarak sınırlı biyokütle mevcudiyeti, taleplerin artışına bağlı olarak ithalata yönelmeleri gerektiği anlamına gelmektedir. Bu da biyokütle temininin sürdürülebilirliğine yönelik bilgilerin ve araştırmaların güncellenmesi gerektiğini ortaya koymaktadır (Kraxner vd., 2017). Smyth vd. (2018)'de de benzer bulgulara ulaşılmıştır.

Çalışmada hasadı artırma stratejisi tek karşı çıkılan stratejidir. Bunun yanında en düşük düzeyde destek bulan stratejiler, hasadı azaltma ve idare sürelerini artırma şeklinde sıralanmıştır. Türkiye ormanlarından üretilen endüstriyel odun miktarı her geçen yıl artarak devam etmektedir. 2017 yılında toplam üretim miktarı 15,5 milyon $\mathrm{m}^{3}$ iken 2020 yılında 24,8 milyon $\mathrm{m}^{3}$ 'e ulaşmıştır (OGM, 2021). Ayrıca OGM Stratejik Planı'nda ormanları geliştirmek, verimliliğini artırmak ve alanlarını geliştirmek stratejik amacı kapsamında endüstriyel ağaçlandırmaya uygunluğu tespit edilen toplam 330.000 hektarlık potansiyel alanda uygulama oranı \%9'dan \%100'e çıkarılması hedefi belirlenmiş durumdadır (OGM, 2018). Endüstriyel ağaçlandırma yapılan alan miktarı belirlenen hedefler doğrultusunda artmaktadır. Örneğin 2013 yılında 2479 ha alan ile başlayan çalışmalar özellikle 2019 ve 2020 yıllarında önemli ölçüde artmış ve sırasıyla 12077 ha ve 19312 ha'ya ulaşmıştır (OGM, 2021). Bu gelişmeler On Birinci Kalkınma Planı'nda (SBB, 2019) “ahşap kullanımının yaygınlaştırılması ve odun hammaddesi talebinin karşılamasına yönelik endüstriyel plantasyonların kurulması” hedefi ile uyumlu olup karbon ikamesi yaklaşımına da hizmet edecek gelişmeler olarak değerlendirilebilecektir. Gürlevik ve Karatepe (2005) tarafından yapılan bir çalışmada da uygun yerlerde endüstriyel ağaçlandırmaların teşvik edilmesi gerektiği vurgulanmıştır. Ancak orman endüstrisinin artan talebini karşılamak ve karbon ikamesine hizmet etmek için daha fazla odun hammaddesi üretimi, ormanların biriktirdiği karbon miktarının azalmasına da neden olacaktır. Ayrıca orman alanlarımızda endüstriyel ağaçlandırmalara uygun araziler oldukça sınırlıdır. Bu açıdan özel sektörün kendi odun ihtiyaçlarını karşılamak üzere endüstriyel ağaçlandırma yatırımlarına yönelmesi ve bu amaçla ihtiyaçları karşılamak için kiralanan veya tapulu arazilerde, özel endüstriyel ağaçlandırma yatırımlarının özendirilmesi; istihdam yaratma, kırsal gönenci artırma ve karbon ticareti açısından da önemli firsatlar yaratabilecektir (Tolunay, 2018).

Çalışma sonuçlarına göre, iklim değişikliği ile mücadelede ormanların korunması ve varlığının artırılarak karbon depolama ve mevcut karbonu koruma işlevleri, orman mühendislerince daha fazla önemsenmektedir. Hasat/üretim temelli yaklaşımlar ise yeterli düzeyde destek bulamamaktadır. Yani ikame ürün olarak ahşap kullanımının teşvik edilmesine yönelik stratejiler, orman mühendislerinde yeterli düzeyde karşılığını 
bulmamıştır.

Bir başka önemli husus, biyoenerji stratejisinin orta düzeyde destek bulmasıdır. Özellikle görev yılı göreli olarak yüksek olan mühendislerin bu stratejiyi destekleme oranları göreli olarak düşük düzeydedir. Bu durumun en önemli nedenleri; biyoenerji sektörünün ülkemizde yeni gelişmeye başlaması, önümüzdeki dönemlerde yeterli hammadde bulunmasına yönelik bu gruplardaki beklentinin düşük düzeyde olması ve sektörün sürdürülebilirliğine duyulan endişe olarak açıklanabilmektedir. $\mathrm{Bu}$ konularda daha fazla eğitim, bilgilendirme/bilinçlendirme çalışmaları ile araştırmaların yapılmasına ihtiyaç bulunmaktadır.

Belirlenen stratejilerden umulan faydaların elde edilebilmesi, orman yönetim stratejilerinin en uygun bileşimini belirlemeye bağlıdır. Bu belirlemelerde mevcut karbonu koruma, daha fazla karbon depolama ve karbon ikamesi yaklaşımlarının doğal tahribatları ve iklim değişikliğini azaltmadaki etkileri ile biyolojik çeşitlilik üzerindeki etkileri öncelikle dikkate alınmalı, ardından bu stratejilerin maliyetleri ve yerel topluluklar üzerindeki ekonomik etkileri değerlendirilmelidir.

\section{Açıklama}

Bu makalede, Isparta Uygulamalı Bilimler Üniversitesi, Lisansüstü Eğitim Enstitüsü, Orman Mühendisliği Anabilim Dalında yürütülmekte olan “Ormancılık Sektöründe İklim Değişikliğine Yönelik Algılar ve İklim Değişikliği ile Mücadele ve Uyum Önlemlerinin Önceliklendirilmesi” başlıklı yüksek lisans tezinin verileri kullanılmıştır.

\section{Kaynaklar}

1. Aladă̆, C., Kaya, B., Tapur, T. (2018). Üniversite öğrencilerinin küresel ısınmada insanın rolü hakkındaki algıları. In Human Society and Education in the Changing World Ed. Y1lmaz E., Sulak S.A., Palet Yayınları, Konya., pp. 209-217.

2. Alkan, H., Özçelik, R., (2019). A research on awareness of climate change and environmental issues. International Conference on Climate Change and Forestry, 88-97, 12-15 November 2019; Antalya.

3. Alkan, H., Korkmaz, M., Eker, M. (2014). Stakeholders' perspectives on utilization of logging residues for bioenergy in Turkey. Croatian Journal of Forest Engineering, 35(2): 153-165.

4. Baş, T. (2010). Anket. Seçkin Yayıncılık, Altıncı Baskı, Ankara.

5. Başsüllü, Ç., Özdemir, E., Semerci, A., İpek A., Tolunay, A. (2014). İklim Değişikliği Müzakerelerinde Ormanc1lı. II. Ulusal Akdeniz Orman ve Çevre Sempozyumu, 518-536, 22-24 Ekim 2014, Isparta.

6. Brown, S., Sathaye, J., Cannell, M., Kauppi, P. (1996). Management of forests for mitigation of greenhouse gas emissions. In: Climate Change 1995: Impacts, Adaptations and Mitigation of Climate Change: ScientificTechnical Analyses. Contribution of Working Group II to the Second Assessment Report of the Intergovernmental Panel on Climate Change Ed. Watson, RT, Zinyowera, MC, Moss RH, Cambridge University Press, New York, pp. 773-797.

7. Çalışkan, S., ve Boydak, M. (2017). Afforestation of arid and semiarid ecosystems in Turkey. Turkish. Journal of Agriculture ve Forestry, 41(5), 317-330.

8. ÇMUSEP (2019). Çölleşmeyle Mücadele Ulusal Stratejisi ve Eylem Planı 2019-2030. Çölleşme ve Erozyonla Mücadele Genel Müdürlüğü Yayınları, Ankara.

9. ÇOB (2008). Ulusal Biyolojik Çeşitlilik Strateji ve Eylem Planı. Çevre ve Orman Bakanlığı, Tasarım Ofset, Ankara.

10. ÇŞB (2010). Türkiye İklim Değişikliği Stratejisi 2010-2023. Türkiye Cumhuriyeti Çevre ve Şehircilik Bakanlı̆̆ı, Ankara.

11. ÇŞB (2012). Türkiye Cumhuriyeti İklim Değişikliği Eylem Planı 2011-2023. Türkiye Cumhuriyeti Çevre ve Şehircilik Bakanlığı, Ankara.

12. Duyar, A. (2018). Türkiye ormanlarındaki rehabilitasyon çalışmalarının orman varlığı ve karbon birikimine katkısına ilişkin bir öngörü. Bartın Orman Fakültesi Dergisi, 20(2): 373-381.

13. Eker, M. (2014). Trends in woody biomass utilization in Turkish Forestry, Croatian Journal of Forest Engineering, 35(2):255-270.

14. Eker, M., Spinelli, R.; Gürlevik, N. (2017). Recovering energy biomass from sustainable forestry using local labor resources. Journal of Cleaner Production, 157:57-64. 
15. Gürlevik, N., Karatepe, Y. (2005). İklim Değişikliği ve Ormancılığımız. Türkiye Ormancılı̆̆ında, Uluslararası Süreçte Acil Eyleme Dönüştürülmesi Gereken Konular, Mevzuat ve Yapılanmaya Yansımaları Sempozyumu, 267-279, 22-24 Aralık 2005, Antalya.

16. IPCC (2013). Climate Change 2013: The Physical Science Basis. In Contribution of Working Group I to the Fifth Assessment Report of the Intergovernmental Panel on Climate Change Ed. Stocker, T.F., D. Qin, G.-K. Plattner, M. Tignor, S.K. Allen, J. Boschung, A. Nauels, Y. Xia, V. Bex and P.M. Midgley, Cambridge University Press, NY, USA, 1535 pp.

17. Korkmaz M. (2018). Public awareness and perceptions of climate change: differences in concern about climate change in the West Mediterranean Region of Turkey. Applied Ecology and Environmental Research, 16(4):4039-4050.

18. Kraxner , F., Fuss, S., Verkerk, P.J. (2017). Is there enough forest biomass available to meet the demands of the forest-based bioeconomy? In Towards a Sustainable European Forest-Based Bioeconomy Assessment and Way Forward, European Forest Institute, Ed. Winkel, G., pp. 51-64.

19. Lejano, R.P., Taveres-Reager, J., Berkes, F. (2013). Climate and narrative: environmental knowledge in everyday life. Environmental Science and Policy, 31(1):61-70.

20. Lutz, J. A., Furniss, T. J., Johnson, D. J., Davies, S. J., Allen, D., Alonso, A., et al. (2018). Global importance of large-diameter trees. Global Ecology and Biogeography, 27(7): 849-864.

21. Mildrexler, D.J., Berner, L.T., Law, B.E., Birdsey, R.A., Moomaw, W.R. (2020). Large trees dominate carbon storage in Forests East of the Cascade Crest in the United States Pacific Northwest. Front. For. Glob. Change, 3:594274.

22. Moomaw, W. R., Masino, S. A., Faison, E. K. (2019). Intact forests in the United States: proforestation mitigates climate change and serves the greatest good. Frontiers in Forests and Global Change, 2(27: 1-10.

23. Nunes, L.J.R., Meireles, C.I.R., Pinto Gomes, C.J., Almeida Ribeiro N.M.C., (2019). Forest management and climate change mitigation: A review on carbon cycle flow models for the sustainability of resources. Sustainability, 11(19):5276.

24. OGM (2018). Orman Genel Müdürlüğü Stratejik Plan (2019-2023). Orman Genel Müdürlüğü, Ankara.

25. OGM (2021). Ormancılık İstatistikleri 2020. Orman Genel Müdürlüğü, Ankara, https://www.ogm.gov.tr/tr/ekutuphane/resmi-istatistikler (10.09.2021).

26. OSB (2014). Ulusal Havza Yönetim Stratejisi. Orman ve Su İşleri Bakanlığı, Ankara.

27. Peterson St-Laurent, G., Hagerman, S., Kozak, R., Hoberg, G. (2018). Public perceptions about climate change mitigation in British Columbia's forest sector. PLOS ONE, 13(4): e0195999.

28. Randall, R. (2009). Loss and climate change: The cost of parallel narratives. Ecopsychology, 1:(3):118-129.

29. SBB (2019). On Birinci Kalkınma Planı (2019-2023). Türkiye Cumhuriyeti Cumhurbaşkanlığı Strateji ve Bütçe Başkanlığı, Ankara.

30. Semenza, J. C., Hall, D. E., Wilson, D. J., Bontempo, B. D., Sailor, D. J., George, L. A. (2008). Public perception of climate change: voluntary mitigation and barriers to behavior change. American journal of preventive medicine, 35(5): 479-487.

31. Serengil, Y. (2018). İklim değişikliği ve karbon yönetimi; Tarım/Orman ve Diğer Arazi kullanımları, İstanbul.

32. Smyth, C.E., Smiley, B.P., Magnan, M., Birdsey, R., Dugan, A.J., Olguin, M., Mascorro, V.S., Kurz, WA. (2018). Climate change mitigation in Canada's forest sector: a spatially explicit case study for two regions. Carbon Balance Management, 13(11):1-12.

33. Steentjes, K., Pidgeon, N., Poortinga, W., Corner, A., Arnold, A., Böhm, G., Mays, C., Poumadère, M., Ruddat, M., Scheer, D., Sonnberger, M., Tvinnereim, E. (2017). European perceptions of climate change (EPCC): Topline findings of a survey conducted in four European countries in 2016. Cardiff: Cardiff University, 69 pages.

34. Tolunay, D. (2011). Total carbon stocks and carbon accumulation in living tree biomass in forest ecosystems of Turkey. Turk J Agric For, 35: 265-279.

35. Tolunay, D. (2018). Odun Hammaddesi Talebinin Karşılanmasında Çare Endüstriyel Ağaçlandırmalar mı? Orman'dan Endüstriye, Orman Mühendisleri Odası İstanbul Şubesi Bülteni, Ağustos-Eylül-Ekim 2018: 3745.

36. URL-1 (2021). Birleşmiş Milletler İklim Değişikliği Çerçeve Sözleşmesi, Çevre ve Şehircilik Bakanlığ1, https://iklim.csb.gov.tr/birlesmis-milletler-iklim-degisikligi-cerceve-sozlesmesi-i-4362 (25.08.2021) 
37. Westerhoff, L., Robinson, J. (2013). Practicing Narratives: Exploring the Meaning and Materiality of Climate Change. Proceedings Transformation in a Changing Climate International Conference in Oslo, 202211, 19-21 June 2013, Oslo.

38. Withana, N. R. P., Auch, E. (2014). Perceptions of climate change risk to forest ecosystems: A case study of Patale Community Forestry User Group, Nepal. International Journal of Environmental, Chemical, Ecological, Geological and Geophysical Engineering, 8(8): 599-606.

39. Xu Z, Smyth CE, Lemprière TC, Rampley GJ, Kurz WA. (2018). Climate change mitigation strategies in the forest sector: biophysical impacts and economic implications in British Columbia, Canada. Mitig Adapt Strateg Glob Change, 23(2):257-90.

40. Zeydanlı, U., Turak, A., Bilgin, C., Kınıkoğlu, Y., Yalçın, S., Doğan, H. (2010). İklim Değişikliği ve Ormancılık: Modellerden Uygulamaya. Doğa Koruma Merkezi, Ankara. 